\title{
Susceptibility of surface texture parameters to acquisition point clouds with digital data processing of data from optical measuring systems
}

\author{
Emilia Bachtiak-Radka ${ }^{1, *}$, Sara Dudzińska ${ }^{1}$, Daniel Grochała ${ }^{1}$, and Stefan Berczyński ${ }^{1}$ \\ ${ }^{1}$ West Pomeranian University of Technology, Faculty of Mechanical Engineering and Mechatronics, al. Piastów 19, 70-310 Szczecin, \\ Poland
}

\begin{abstract}
Digital processing of the recorded point clouds on innovative surfaces could facilitate the operator's planning of the metrological process and give more freedom in the assessment of the surface texture. The current state of knowledge about surface characteristics, precision and quality of measurements and especially the repeatability of measurements - not only in the laboratory environment but also in the industry pose a big challenge. The paper presents research works related to the identification of the impact of the method of acquisition point clouds using digital data processing on surface texture. The main assumption of the paper was to carry out, according to the prepared plan of the experiment, the series of sample measurements with the use of the optical measuring systems AltiSurf A520 in the Laboratory of Surface Topography at the West Pomeranian University of Technology in Szczecin. The next task was to determine the impact of the digital data processing strategy in order to identify the significance of the impact (conditions and methods of filtration), which in practice largely determines the repeatability and reproducibility of the parameter values of the geometry surface structure.
\end{abstract}

\section{Introduction}

Digital processing of registered point clouds on innovative and precise surfaces enables operators to develop a planning process for metrological procedures and gives more freedom in the assessment of surface texture. Registration of the point clouds without shape errors and surface roughness allows resigning from the digital processing, while simultaneously, the determined surface topography parameters become free from an accidental impact of the operator [14]. Despite this, it should be emphasised that currently, it is impossible to register point clouds on precise surfaces using optical measuring systems. Given that an ideal method for registering a point clouds without shape errors, the methodology for determination of surface texture parameter values becomes much simpler. SG parameter values registered without the threshold values fixing, levelling out and filtration should be reproducible and repeatable for different measurement systems offered by different manufacturers. It should also enable simple classification of digital measuring instruments. The current state of knowledge about surface characteristics, the accuracy and quality of measurements and above all their reproducibility, not only in the laboratory environment but also in the industry puts a lot of challenges $[15,16]$. The aim of this study was to identify the method for processing the point cloud using the digital data processing according to a prepared experiment plan of measurements on the AltiSurf A520 optical measuring instrument in the Surface Topography Laboratory at the West Pomeranian University of Technology in Szczecin. The next task was to determine the impact of digital data processing strategies (conditions and methods of filtration), which in practice means the repeatability and reproducibility of the determined values of surface texture parameters [12]. The research was carried out on the roughness standards. The experiment employed the strategy of processing the point clouds by means of the digital data processing for individual stages: artificial truncation of the surface, levelling the surface, form removal on the surface as well surface filtering using AltiMap PREMIUM version 6.2 software. The study objective was to assess the effect of surface texture amplitude parameters on the coefficient of variation at particular stages of point cloud processing. In recent years the market has increased the offer of optical equipment for measuring the surface topography based on the effect of phase shift [4] or effect of confocal chromatic light [5]. The available equipment also uses the effect of focusing and reflection of the monochrome light on the measured surface $[6,7]$. Technical documentation which is included for this type of equipment and international standards $[4,5,11]$ do not describe the conditions of acquiring points on the measured surface. The norms define only the basic rules and recommendations $[8,9,11]$. It should therefore appear that that the extremely wide scope of applications of this type of equipment necessitates every time out defining new settings individually for each measured

${ }^{*}$ Corresponding author: emilia.bachtiak-radka@,zut.edu.pl 
object. A number of various factors affect the readings of point cloud coordinates, such as the measuring system, the environment or simply the operator [1-3]. In the research conducted in the Surface Topography Laboratory (LTP) at the West Pomeranian University of Technology (ZUT) in Szczecin, we focused on specifying conditions for acquiring a point cloud for the surface of metal objects. Based on the obtained results we defined the coefficient of variation for individual experimental setups with the aim of investigating the significance of digital data processing method on differentiation of surface texture amplitude parameters. The experiment was carried out in variable but controlled environmental conditions using modern AltiSurf A520 measuring equipment from Altimet (Fig. 1) and the surface roughness pattern with $C 3$ type sinusoidal grooves (according to PN-EN ISO 4536-1) Hommel-Etamic No. 3442.

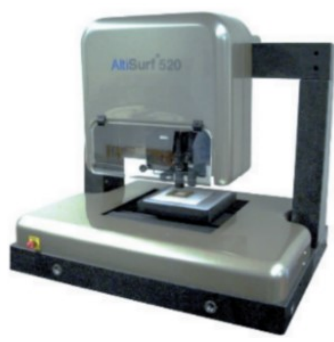

Fig. 1. Profilometer AltiSurf A520 with modular construction enabling optical and contact measurements.

The AltiSurf A520 is multisensory equipment for measurements of surface topography. The construction of the equipment is based on table and gate made of granite. The table movements are realised in the XY plane by means of motorised drives with the resolution of $0.1 \mu \mathrm{m}$. The resolution of the mechanism used for Zaxis drive is $0.5 \mu \mathrm{m}$. Depending on the used sensor the equipment uses the effect of interferometric [4, 13] or confocal microscopy $[5,13]$. It was resolved that for the purpose of the conducted research, the principles of optical confocal chromatic imaging will be employed, in order to ensure the high resolution of points collected along the optical axis of the instrument. Using a special shutter system in the optical measuring axis for a photoelectric transducer it only hits light beam focused and reflected in the measured surface point. Chromatic confocal sensors can be used in the measurement of objects made of any material.

\section{Research methodology}

Measurements of the roughness texture were carried out on AltiSurf A520 measuring machine, equipped with CL2 confocal sensor with the measuring range $0 \div 400$ $\mu \mathrm{m}$. The area of surface scanning was $4 \mathrm{~mm} \times 4 \mathrm{~mm}$, sampling in the $\mathrm{X}$-axis $6 \mu \mathrm{m}$, sampling in the $\mathrm{Y}$-axis $0.6 \mu \mathrm{m}$ with a scanning speed of $120 \mu \mathrm{m} / \mathrm{s}$ while the brightness of the LED was $100 \%$ of the lighting power, and finally, the ambient temperature was constant and equalled $21{ }^{\circ} \mathrm{C}$. Prior to proper measurements the machine performed the first test scan after which the right sequence of the measurement program was determined. The test measurement lasted for about 30 minutes, which aimed to stabilise the environment after setting the machine and the operator's exit from the laboratory. To achieve the main aim of the paper the prepared research object included five stages of processing the point cloud directly after the measurement with use confocal microscope which is part of the typical procedure for determining surface texture parameters by means of the digital processing (Fig. 2, Table 1).

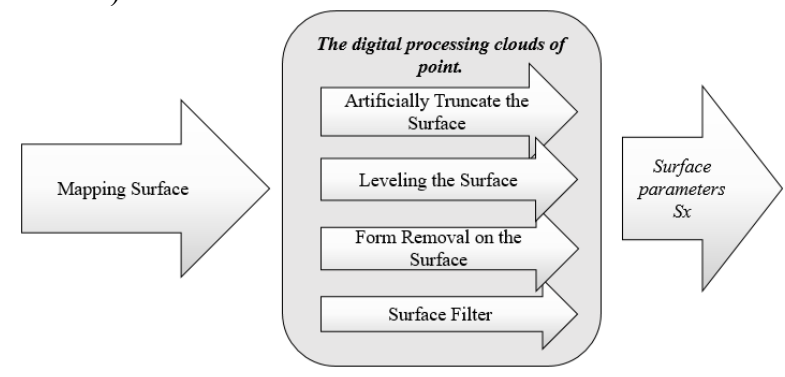

Fig. 2. Complex research object.

Table 1. Description of selected input factors adopted.

\begin{tabular}{|c|c|c|}
\hline & Description of the factor & Range \\
\hline 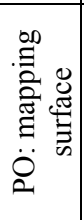 & $\begin{array}{l}\text { A set of points (point cloud) } \\
\text { describing coordinates of the } \\
\text { characteristic points of the } \\
\text { surface in accordance with the } \\
\text { measurement plan prepared } \\
\text { by an operator. }\end{array}$ & - \\
\hline 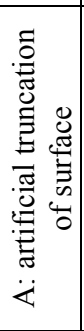 & $\begin{array}{l}\text { The operator allows you to } \\
\text { artificially truncate the } \\
\text { surface (at the top and/or } \\
\text { bottom) at a given altitude. } \\
\text { This operator is especially } \\
\text { useful for reducing peaks that } \\
\text { are too large and that } \\
\text { therefore hide other reliefs, or } \\
\text { for simulating a wear process. }\end{array}$ & $\begin{array}{l}1.0 .01-99.99 \\
2.0 .05-99.95 \\
3.0 .10-99.90\end{array}$ \\
\hline 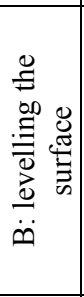 & $\begin{array}{l}\text { This operator can be used to } \\
\text { remove the general slope of a } \\
\text { surface. This slope can be the } \\
\text { result of a measurement that } \\
\text { was not strictly horizontal. }\end{array}$ & $\begin{array}{l}\text { 1. Least Squares } \\
\text { (LS) Plane Method } \\
\text { (By Rotation) } \\
\text { 2. Least Squares } \\
\text { (LS) Plane Method } \\
\text { (by Subtraction) } \\
\text { 3. } 3 \text { Points Method } \\
\text { (10 points) }\end{array}$ \\
\hline 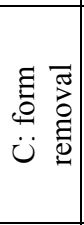 & $\begin{array}{l}\text { For some operators or studies } \\
\text { on surfaces, you may want to } \\
\text { define an area to exclude } \\
\text { from an operation or an area } \\
\text { to use as a reference zone. }\end{array}$ & $\begin{array}{l}\text { 1. Polynomials of } \\
\text { power }=2 \\
\text { 2. Polynomials of } \\
\text { power }=3 \\
\text { 3. Polynomials of } \\
\text { power }=4\end{array}$ \\
\hline 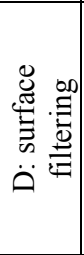 & $\begin{array}{l}\text { Filtering (in metrology) is an } \\
\text { operation that transforms a } \\
\text { profile or a surface in order to } \\
\text { remove those components of } \\
\text { the surface relief that are of } \\
\text { no or little interest for the } \\
\text { analysis of a measurement. }\end{array}$ & $\begin{array}{l}\text { 1. Gauss Filter } \\
\text { (CutOff } 0.8 \mathrm{~mm}) \\
\text { 2. Coarse Gaussian } \\
\text { filter (CutOff } \\
0.8 \mathrm{~mm}) \\
\text { 3. Spline Filter } \\
\text { (CutOff } 0.8 \mathrm{~mm})\end{array}$ \\
\hline
\end{tabular}

The variability of individual stages of point clouds digital processing is representative of all commercially available equipment for surface texture testing, and in 
accordance with $[5,12]$. In accordance with the test plan we carried out a series of 27 experimental setups (Table 3) which was executed in AltiMap PREMIUM 6.2 software (Table 2).

Table 2. Methods of data processing and filtering software AltiMap PREMIUM 6.2

\begin{tabular}{|c|c|}
\hline & $\begin{array}{l}\text { Methods of data processing and filtering } \\
\text { software AltiMap PREMIUM } 6.2\end{array}$ \\
\hline 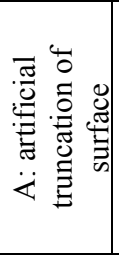 & $\begin{array}{l}\text { Artificial truncation of the point clouds for the } \\
\text { surface is given as a bearing surface ratio from } \\
0.01,0.05 \text { and } 0.1 \text { (from the top, and from the } \\
\text { bottom at the same time). Modify only of the } 0.02 \text {, } \\
0.1 \text { and } 0.2 \% \text { of all the data points from the surface } \\
\text { can increase the compression on the vertical scale } \\
\text { in a very spectacular way }\end{array}$ \\
\hline 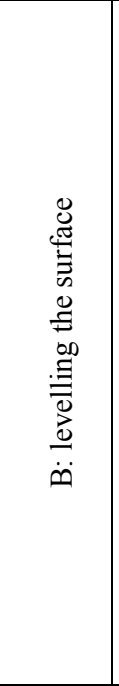 & $\begin{array}{l}\text { Methods to Define the Plane to Remove or } \\
\text { levelling the surface: } \\
\text { a) Least Squares (LS) Plane Method - removing } \\
\text { the least squares plane consists in calculating the } \\
\text { equation of the P plane which minimises the sum of } \\
\text { the squares of the basic distances d(x,y) at the point } \\
(\mathrm{x}, \mathrm{y}, \mathrm{z}) \text {, d }(\mathrm{x}, \mathrm{y}) \text { being the distance between the point } \\
(\mathrm{x}, \mathrm{y}, \mathrm{z}) \text { of the surface and the point }(\mathrm{x}, \mathrm{y}, \mathrm{z} \text { ') of the } \\
\text { plane. } \\
\text { b) } 3 \text { Points Method - the plane is simply defined by } \\
\text { three user-defined points on the surface. } \\
\text { Methods to Remove the Plane from the Surface: } \\
\text { a) By Subtraction - the levelling is carried out by } \\
\text { subtracting the P plane from the surface point by } \\
\text { point. } \\
\text { b) By Rotation - the angle between the P plane and } \\
\text { the horizontal plane is used to rotate the surface so } \\
\text { that it is as horizontal as possible. }\end{array}$ \\
\hline 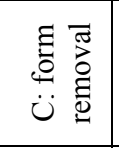 & $\begin{array}{l}\text { Suppression of any Shape by Polynomial } \\
\text { Approximation - this method consists in searching } \\
\text { the polynomial degree defined by the user which is } \\
\text { closer to the original surface. }\end{array}$ \\
\hline 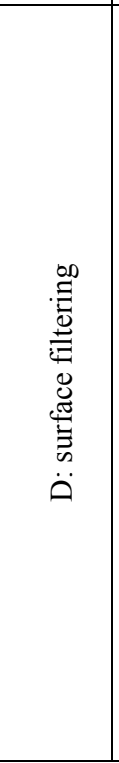 & $\begin{array}{l}\text { Gaussian Filter (ISO 11562) } \\
\text { The Gaussian filter is the transfer function of the } \\
\text { Gaussian filter showing } 50 \% \text { attenuation at the cut- } \\
\text { off frequency. Half of the length of a cut-off is } \\
\text { removed from both extremities of a filtered profile. } \\
\text { It is, therefore, one cut-off length shorter than the } \\
\text { primary profile. In the case of a surface, the } \\
\text { removal also applies to the Y-axis by removing } \\
\text { lines above and below the surface. } \\
\text { Robust Gaussian filter (ISO/TS 16610-31) } \\
\text { The term "robust" means that the filter is capable of } \\
\text { generating a mean line that is undisturbed by } \\
\text { accidental or local features of a profile. This filter } \\
\text { enables filtering without loss at the edges. } \\
\text { Cubic Spline Filter (ISO/TS 16610-22) } \\
\text { It is a filter that is very close to the Gaussian filter, } \\
\text { which also attenuates of 50\% at the cut-off } \\
\text { frequency. Its main interest is that it is constructed } \\
\text { to filter a profile without losing the edges. } \\
\text { Therefore, the filtered profile has the same size as } \\
\text { the primary profile. }\end{array}$ \\
\hline
\end{tabular}

The tests have produced twenty-seven sets of points from which the values of surface texture indicators were determined, according to the standard [8]. In the further part of the paper, methods of statistical processing of experimental data on the example of the surface indicator value Sq. Analogous scheme proceedings were applied for determining the impact operator during statistical processing of other values of surface texture.

Table 3. Individual codified stages of the experiment plan

\begin{tabular}{|c|c|c|c|}
\hline & -1 & $\mathbf{0}$ & 1 \\
\hline $\begin{array}{l}\text { A: artificial } \\
\text { truncation } \\
\text { of surface }\end{array}$ & $0.01-99.99$ & $0.05-99.95$ & $\begin{array}{l}0.10- \\
99.90\end{array}$ \\
\hline $\begin{array}{l}\text { B: levelling } \\
\text { the surface }\end{array}$ & $\begin{array}{c}\text { Least Squares } \\
\text { (LS) Plane } \\
\text { Method (By } \\
\text { Rotation) }\end{array}$ & $\begin{array}{l}\text { Least Squares } \\
\text { (LS) Plane } \\
\text { Method (by } \\
\text { Subtraction) }\end{array}$ & $\begin{array}{l}3 \text { Points } \\
\text { Method } \\
(10 \\
\text { points })\end{array}$ \\
\hline $\begin{array}{l}\text { C: form } \\
\text { removal }\end{array}$ & $\begin{array}{l}\text { Polynomials } \\
\text { of power }=2\end{array}$ & $\begin{array}{l}\text { Polynomials } \\
\text { of power }=3\end{array}$ & $\begin{array}{c}\text { Polynomi } \\
\text { als of } \\
\text { power }=4\end{array}$ \\
\hline $\begin{array}{l}\text { D: surface } \\
\text { filtering }\end{array}$ & $\begin{array}{l}\text { Gauss Filter } \\
\text { (CutOff } \\
0.8 \mathrm{~mm})\end{array}$ & $\begin{array}{c}\text { Coarse } \\
\text { Gaussian filter } \\
\text { (CutOff } \\
0.8 \mathrm{~mm})\end{array}$ & $\begin{array}{l}\text { Spline } \\
\text { Filter } \\
\text { (CutOff } \\
0.8 \mathrm{~mm}) \\
\end{array}$ \\
\hline
\end{tabular}

For example, $\mathrm{Sq}$ i.e. mean square root of surface points determined in relation to the reference surface as the standard deviation of the unevenness of the surface [7]. The value $\mathrm{Sq}$ is defined similarly to the mean square deviation of the $\mathrm{Rq}$ mapped profile in $2 \mathrm{D}$ :

$$
S q=\sqrt{\frac{1}{M \cdot N} \sum_{j=1}^{N} \sum_{i=1}^{M} \theta^{2}\left(x_{i}, y_{j}\right)}
$$

$M \cdot N$ - size of the sampling matrix

$\theta\left(x_{i}, y_{j}\right)-$ residual area (supporting surface)

Examples of surface images obtained from tests are shown in Fig. 3.

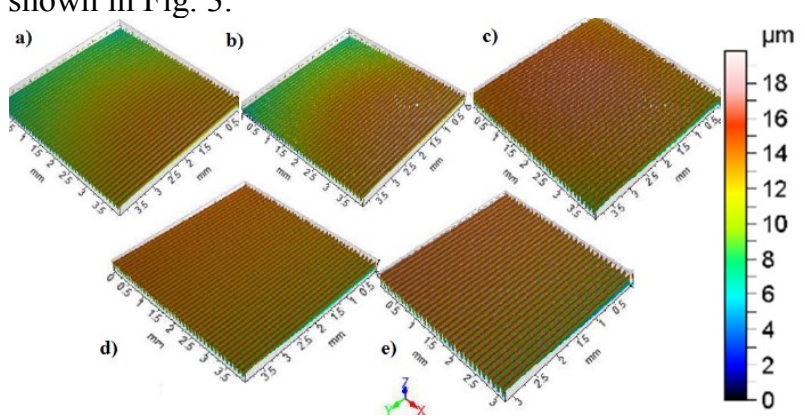

Fig. 3. An example of the surface image obtained from tests, a) mapping surface, $b$ ) artificial truncation of surface, c) levelling the surface, d) form removal, e) surface filtering.

\section{Analysis of test results}

Table 4 shows the experiment plan and the determined values of the Sq parameter, Fig. 4 - the juxtaposition of mean square height parameters (mean square deviation of surface points $\mathrm{Sq}$ ) the juxtaposition of mean square height parameters (mean square deviation of surface points $\mathrm{Sq}$ ) obtained from individual experiments carried out in accordance with the test plan, and in Fig. 5 - exemplary surface views obtained for individual stages of the point clouds processing of data. 
Table 4. Test plan with actual values of input and output parameters $\mathrm{Sq}(\mathrm{Sq}$ - mean square root area).

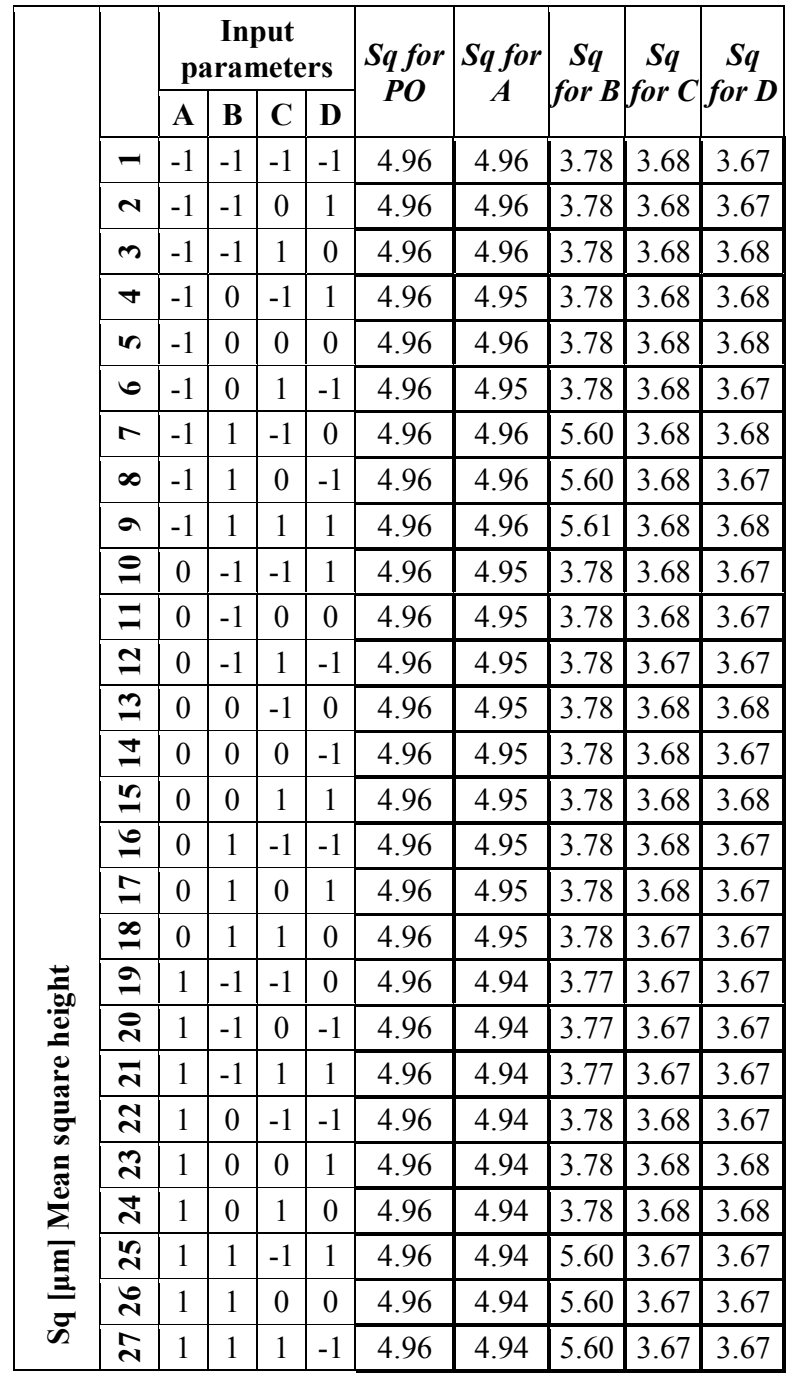

For better illustration, set of charts showing the Sq values obtained from individual test setups show the effect of particular stages of digital processing of the registered point clouds(Fig. 4).

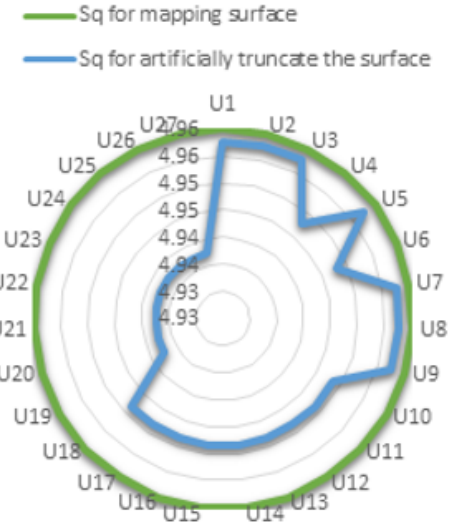

Fig. 4 Chart of changes in extreme values of Sq depending on the adopted method of artificial truncation of surface.

It was shown that by adopting the 3 Points Method (10 points) in levelling the surface effect in significant differences in the value of indicators: for $\mathrm{Sq}$ - it was even $67 \%$ - Fig. 5 .

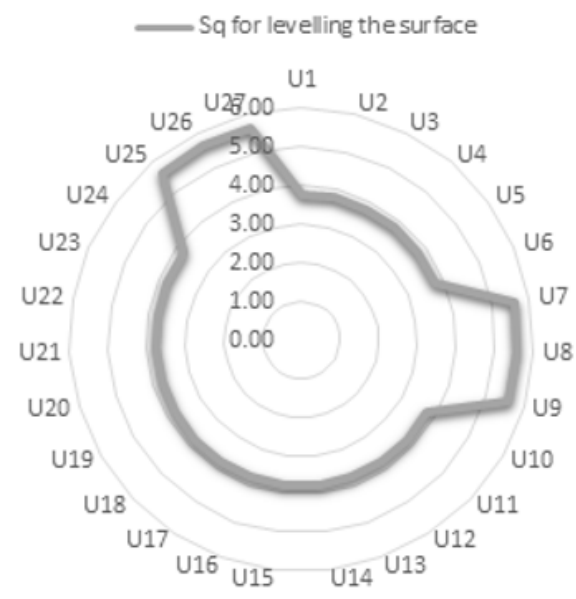

Fig. 5. Chart of changes Sq depending on the method used to remove surface levelling .

In most cases, form removal methodology parallelism of the surface $\mathrm{Sq}$ indicator values are reduced, however, with the arrangement 2, 24, 25 after filtration, the values remain on the same level.

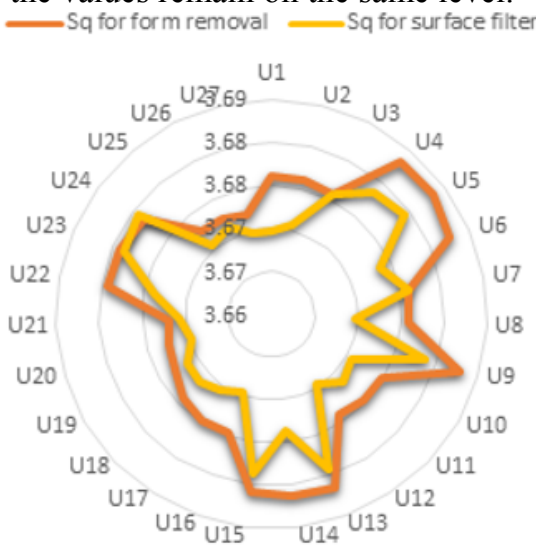

Fig. 6. Chart of Sq parameter changes depending on the method form removal and filtering out the roughness.

In no case was unnatural surface structure the result of measurement errors or other undefined (systematic) impact. Table 3 shows the results for the mean square surface deviation Sq. Similar calculations were repeated for other surface texture parameters analysed - for 27 systems; the average values were summarised in Table 5.

For better illustration of changes resulting from the application of subsequent stages during the digital processing of the registered point clouds, the coefficient of variation of KSx surface condition was determined, where:

$$
K S x=\frac{S x_{P O}}{S x_{x}}
$$

SxPO - the value of the surface texture parameter for the mapping surface

$S x_{x}$ - the value of the surface texture parameter after the specified the digital operation of date.

The determined values of the variation coefficients for Sq are presented in Table 6 
Table 6. The coefficient variation of Sq obtained from tests.

\begin{tabular}{|c|c|c|c|c|c|c|c|c|c|c|c|c|}
\hline $\begin{array}{l}\stackrel{\Xi}{\Xi} \\
\text { Z }\end{array}$ & $\frac{\pi}{5}$ & $\begin{array}{l}0 \\
0 \\
\vdots \\
5 \\
5\end{array}$ & 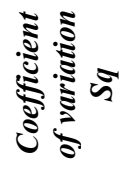 & $\sum_{5}^{\dot{b}} \infty$ & $\begin{array}{l}0 \\
0 \\
\vdots \\
0 \\
5 \\
5\end{array}$ & 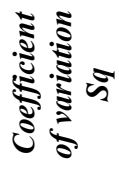 & $\frac{0}{\vdots}$ & $\begin{array}{l}0 \\
2 \\
\vdots \\
5 \\
5\end{array}$ & 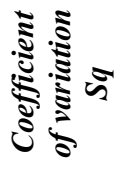 & $\frac{0}{\vdots}$ & $\begin{array}{l}0 \\
2 \\
5 \\
5 \\
5 \\
5\end{array}$ & 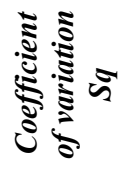 \\
\hline U1 & 4.96 & 4.96 & 100.05 & 3.78 & 4.96 & 131.32 & 3.68 & 4.96 & 134.92 & 3.67 & 4.96 & 135.16 \\
\hline U2 & 4.96 & 4.96 & 100.05 & 3.78 & 4.96 & 131.32 & 3.68 & 4.96 & 134.93 & 3.67 & 4.96 & 135.12 \\
\hline U3 & 4.96 & 4.96 & 100.05 & 3.78 & 4.96 & 131.32 & 3.68 & 4.96 & 134.94 & 3.68 & 4.96 & 134.94 \\
\hline U4 & 4.95 & 4.96 & 100.24 & 3.78 & 4.96 & 131.17 & 3.68 & 4.96 & 134.66 & 3.68 & 4.96 & 134.83 \\
\hline U5 & 4.96 & 4.96 & 100.05 & 3.78 & 4.96 & 131.08 & 3.68 & 4.96 & 134.66 & 3.68 & 4.96 & 134.81 \\
\hline U6 & 4.95 & 4.96 & 100.24 & 3.78 & 4.96 & 131.17 & 3.68 & 4.96 & 134.69 & 3.67 & 4.96 & 135.01 \\
\hline U7 & 4.96 & 4.96 & 100.05 & 5.60 & 4.96 & 88.57 & 3.68 & 4.96 & 134.92 & 3.68 & 4.96 & 134.92 \\
\hline U8 & 4.96 & 4.96 & 100.05 & 5.60 & 4.96 & 88.57 & 3.68 & 4.96 & 134.93 & 3.67 & 4.96 & 135.16 \\
\hline U9 & 4.96 & 4.96 & 100.05 & 5.61 & 4.96 & 88.47 & 3.68 & 4.96 & 134.68 & 3.68 & 4.96 & 134.83 \\
\hline U10 & 4.95 & 4.96 & 100.23 & 3.77 & 4.96 & 131.41 & 3.67 & 4.96 & 134.97 & 3.67 & 4.96 & 135.13 \\
\hline U11 & 4.95 & 4.96 & 100.23 & 3.77 & 4.96 & 131.41 & 3.67 & 4.96 & 134.98 & 3.67 & 4.96 & 135.10 \\
\hline U12 & 4.95 & 4.96 & 100.23 & 3.77 & 4.96 & 131.41 & 3.67 & 4.96 & 135.00 & 3.67 & 4.96 & 135.16 \\
\hline U13 & 4.95 & 4.96 & 100.23 & 3.78 & 4.96 & 131.18 & 3.68 & 4.96 & 134.72 & 3.68 & 4.96 & 134.81 \\
\hline U14 & 4.95 & 4.96 & 100.23 & 3.78 & 4.96 & 131.18 & 3.68 & 4.96 & 134.73 & 3.67 & 4.96 & 135.01 \\
\hline U15 & 4.95 & 4.96 & 100.23 & 3.78 & 4.96 & 131.18 & 3.68 & 4.96 & 134.75 & 3.68 & 4.96 & 134.83 \\
\hline U16 & 4.95 & 4.96 & 100.23 & 3.77 & 4.96 & 131.41 & 3.67 & 4.96 & 134.97 & 3.67 & 4.96 & 135.16 \\
\hline U17 & 4.95 & 4.96 & 100.23 & 3.77 & 4.96 & 131.41 & 3.67 & 4.96 & 134.97 & 3.67 & 4.96 & 135.13 \\
\hline U18 & 4.95 & 4.96 & 100.23 & 3.77 & 4.96 & 131.41 & 3.67 & 4.96 & 135.00 & 3.67 & 4.96 & 135.10 \\
\hline U19 & 4.94 & 4.96 & 100.46 & 3.77 & 4.96 & 131.51 & 3.67 & 4.96 & 135.05 & 3.67 & 4.96 & 135.10 \\
\hline U20 & 4.94 & 4.96 & 100.46 & 3.77 & 4.96 & 131.51 & 3.67 & 4.96 & 135.06 & 3.67 & 4.96 & 135.16 \\
\hline U21 & 4.94 & 4.96 & 100.46 & 3.77 & 4.96 & 131.51 & 3.67 & 4.96 & 135.08 & 3.67 & 4.96 & 135.12 \\
\hline U22 & 4.94 & 4.96 & 100.46 & 3.78 & 4.96 & 131.30 & 3.68 & 4.96 & 134.81 & 3.67 & 4.96 & 135.01 \\
\hline $\mathbf{U} 23$ & 4.94 & 4.96 & 100.46 & 3.78 & 4.96 & 131.30 & 3.68 & 4.96 & 134.82 & 3.68 & 4.96 & 134.83 \\
\hline U24 & 4.94 & 4.96 & 100.46 & 3.78 & 4.96 & 131.30 & 3.68 & 4.96 & 134.84 & 3.68 & 4.96 & 134.81 \\
\hline $\mathbf{U 2 5}$ & 4.94 & 4.96 & 100.46 & 5.60 & 4.96 & 88.51 & 3.67 & 4.96 & 135.05 & 3.67 & 4.96 & 135.13 \\
\hline U26 & 4.94 & 4.96 & 100.46 & 5.60 & 4.96 & 88.51 & 3.67 & 4.96 & 135.06 & 3.67 & 4.96 & 135.10 \\
\hline U27 & 4.94 & 4.96 & 100.46 & 5.60 & 4.96 & 88.51 & 3.67 & 4.96 & 135.08 & 3.67 & 4.96 & 135.16 \\
\hline
\end{tabular}

The aim of the investigation was the assessment of the impact of individual stages processing point cloud on the value of selected surface texture parameters. During analysis we observed the following trends. Taking into account the sequence of stages, which were made during the digital data processing, it should be noted that for 27 layouts the mapping surface was characterised by the largest parameter indications. The first stage data processing was artificial truncation of surface; for scheme $1-9$ the parameter value decreased by $0.05 \%$ regarding surface mapping, however, the same data processing for schemes 4 and 6 the values decreased by $0.24 \%$. In the case of the schemes $10-18$ artificial truncation of surface amounted to $0.05-99.95$ and the values of the Sq parameter were reduced by $0.23 \%$. The data was then levelled using three different methods. It is caused by the angle of inclination of the surface after levelling. The case of other schemes application the next stage of digital data processing by the AltiMap PREMIUM 6.2 software, the Sq parameter value was reduced to approximately $31 \%$ in particular schemes. Another element from input parameters is to remove the surface shape. Thanks to the application, in this treatment we monitored the effect on the order of the polynomial the value of parameter $\mathrm{Sq}$ - reduced by 34$35 \%$ from the mapping surface. The reduction of parameter values by filtration of $\mathrm{Sq}$ values from the mapped value is reduced by approximately $35 \%$.
It should be noted that that at the moment there are no explicitly written procedures for acquiring point clouds and their digital processing in relevant standards, therefore, each operator has certain flexibility in the processing of data. Nevertheless, attention should be paid to repeatability and reproducibility of measurement results as one of the factors affecting is the same measurement procedure; therefore, metrologists need to describe the research methodology after each report.

\section{Summary}

In the Surface Topography Laboratory we attempted to verify the levels of significant influence on processing point clouds in AltiMap PREMIUM 6.2 software. We should bear in mind that there are no standards and guidelines regarding how to conduct the acquisition of point clouds, as well as the digital processing of data; therefore operators have a certain degree of freedom in selecting the significant influence on the measurement result. The operator can decide about the widest range of reduction parameters of the geometric structure of the surface.

In summary, it can be concluded that for the same data the discrepancy in the final values of indicators may reach up to $200 \%$, which may be the reason escalation of quality problems in industry and a source of misunderstanding when attempting to reproduce the results of research described in scientific publications. At 
the moment, the methodology as well as the order together with the accepted values at every stage of the digital processing of the point cloud should be described after each test. Therefore, it would be best to implement the One Way methodology for the digital processing of point clouds, to create a standardised form that would guarantee repeatable values of surface texture indicators. The paper focuses solely on the digital data processing but from previous research, we know that acquisition conditions can significantly affect [10] the set of point clouds. The present study aimed to eliminate all the factors that are the source of unnecessary variability in surface texture 3D analysis using optical imaging methods.

\section{References}

1. T. Miller, S. Adamczak, J. Świderski, M. Wieczorowski, A. Łętocha A., B. Gapiński, Influence of temperature gradient on surface texture measurements with the use of profilometry. Bulletin of the Polish Academy of Sciences - Technical Sciences. 65 (2017)

2. M. Wieczorowski, B. Gapiński, K. Grochalski, T. Miller, Teoretyczne aspekty analizy wybranych źródet błędów w profilowych pomiarach nierówności powierzchni. Mechanik. 4 (2017): s. 335-338

3. T. Miller, Źródła niewiarygodności pomiarów topografii powierzchni, Mechanik. 11 (2016)

4. PN-EN ISO 25178-603:2013-12. Specyfikacje geometrii wyrobów (GPS). Struktura geometryczna powierzchni: Przestrzenna - Część 603. Charakterystyki nominalne przyrząów bezstykowych (mikroskopów interferometrycznych z korekcja fazy)

5. PN-EN ISO 25178-602:2010. Specyfikacje geometrii wyrobów. Struktura geometryczna powierzchni: Przestrzenna - Część 602. Charakterystyki nominalne przyrzadów bezstykowych (z czujnikiem chromatycznym konfokalnym)

6. M. Wieczorowski, Metrologia nierówności powierzchni - metody $i$ systemy. ZAPOL Szczecin, Sobczyk Sp.J., (2013)
7. P. Pawlus, M. Wieczorowski, T. Mathia, The errors of stylus methods in surface topography measurments. ZAPOL Szczecin, Sobczyk Sp.J., (2014)

8. PN-EN ISO 25178-2:2012. Specyfikacje geometrii wyrobów (GPS). Struktura geometryczna powierzchni: Przestrzenna - Część 2. Terminy, definicje $i$ parametry struktury geometrycznej powierzchni.

9. ISO 25178-1:2016 (en). Geometrical product specifications (GPS). Surface texture: Areal Part 1. Indication of surface texture

10. E. Bachtiak-Radka, S. Dudzińska, D. Grochała, S. Berczyński, Susceptibility of SPG parameters to the environment conditions and the method of acquisition of cloud of points with optical measuring systems applied. Mechanik. 8-9 (2017)

11. R.K. Leach, C.L. Giusca, H. Haitjema, C. Evans, $\mathrm{X}$. Jiang, Calibration and verification of areal surface texture measuring instruments. CIRP Annals - Manufacturing Technology 64 (2015)

12. R. Leach, The measurement of surface texture using stylus instruments. in Measurement Good Practice Guide, Engineering Measurement Division National Physical Laboratory, 37 (2014)

13. D.J. Whitehouse, A revised philosophy of surface measuring systems. Proceedings of the Institution of Mechanical Engineers, Part C: Journal of Mechanical Engineering Science 202 (1988)

14. N.K.P. Neubert, Instrument Transducers: An Introduction to Their Performance and Design, Oxford University Press. Oxford, (1963)

15. Dudzińska S., Szydłowski M., Grochała D., Emilia Bachtiak-Radka, Application of Correlation Function for Analysis of Surface Structure Shaping by Hybrid Manufacturing Technology. Advances in Manufacturing. 01 (2018)

16. Grochała D., Berczyński S., Grządziel Z, Modeling of burnishing thermally toughened X42CrMo4 steel with a ceramic $\mathrm{ZrO} 2$ ball. Archives of Civil and Mechanical Engineering. 09 (2017) 